\title{
Radiological Terrorism Scenarios
}

\section{Dear Editor:}

Threats of radiological, biological and chemical terrorism certainly are not new; one only has to look at examples such as the smallpox-infected blankets that were used to kill Native Americans, nerve gas, World War I, and chemicals in Iraq. These threats received renewed attention after news about the use of depleted uranium during NATO's "humanitarian" war in Yugoslavia was reported. As a result, knowledgeable people thought the cancer rate would rise, especially in Kosovo. Weak reporting systems made it difficult to monitor potential birth defects. Radiation damage is talked about openly in the Serbian north, but is met with a curtain of silence in the Albanian south of Kosovo, where locals are more likely to discuss the great number of landmines left by the Serbian army.

Fallout from the Chernobyl disaster was detected throughout Europe, and in its aftermath, it has resulted in increased incidences of thyroid cancer, regional poverty, and considerable mental disturbance. The terrorist attacks of 11 September 2001 demonstrated that terrorist groups are capable of causing mass casualties, while the destruction of nuclear facilities, (i.e., Iraq in the past) and the possible destruction of Iran's nuclear facilities did little to calm the public's fear. After the death of a Russian spy in London, radiological terrorism again caught the public eye when Greek tourists were suspected of being poisoned by the same source. Fortunately, the tourists tested negatively for radioactive polonium. Meanwhile, the preparedness of health facilities for disasters is not adequate; the January 2007 rocket attack in Greece was a disturbing incident that illustrated this fact.

The thought of a release of radioactive agents among a civilian population increases fear in the public and in politicians. To allay fear and lessen panic, it is necessary to estimate the probability of the occurrence of such an attack or incident, as well as the economic, social, and political effects and impact, and to improve regional and national preparedness and response ability. We must ask ourselves why radiological terrorism has become such a prominent and frightening subject, and what does this threat mean today? We must come to understand that much of this interdisciplinary problem belongs to the complex sphere of public health, and is in need of reinforcement.

Radioactive materials are used on a daily basis throughout Europe where, purportedly, they are regulated and secure. Yet, there is considerable evidence that suggests the opposite. Recently, this was demonstrated in the case of the Russian spy, and is reminiscent of previously alleged cases, including the 1993 placement by the Russian mafia of a gamma ray source in the office of a Moscow businessman. The acquisition and use of a radioactive source implies considerable knowledge of radioisotope waste disposal, ballistics, and other skills, and its illegal acquisition is part of global corruption, which also implies the support of misguided scientists and demands increased attention.
Radioactive sources are easier to access than are materials needed to perpetrate chemical, biological, or nuclear terrorism. Recent geopolitical events have made the access and acquisition of radioactive materials possible, as was the case in the "lost" catalogue of sources after the collapse of the Soviet Union. Organized crime and terrorist agents may have stolen the materials that disappeared. The first widely reported incident of radiological terrorism occurred in 1995, when Chechen rebels placed a container with a small quantity of cesium-137 in a Moscow park, and then notified a Russian television crew, which easily located the source.

Radiological terrorism is possible, now more than ever, due to the major threat of an explosion of radiological dispersal device or a radiological dispersal rocket over cities. They are examples of "weapons of mass disnuption", terminology used to designate a dirty bomb. If detonated over a civilian population, it would create panic and disrupt normal function by producing widespread physical destruction and a number of deaths. To date, there have been no successful incidents of radiological terrorism using either a dirty bomb or rocket. It is alleged that in 1987, Iraq tested a radiological weapon, that did not produce a high enough radiation level and was considered a failure. Furthermore, the accuracy of its release over the selected target area was not controllable.

In 1999, unidentified criminals attempted to steal a $200 \mathrm{~g}$ container of radioactive material from a chemical factory in Chechnya. Even though each criminal carried the container for only a few minutes, one of them died half an hour after radiation exposure, while another was hospitalized in critical condition. It was an alarming event because of the inference that the radioactive material was actually destined for turbulent Kosovo in the heart of the Balkans. In 2005, it was reported that an arms dealer in Bender, Transnistria, offered to sell a journalist posing as a member of an Algerian militant group three Alazan rockets equipped with radioactive warheads. These rockets were designed by Soviet scientists in a failed attempt to prevent hail. Today, the use of the Internet for signal transmission by European terrorists has alarmed secret service agencies.

Currently, there are rumors of plans to destroy Iranian nuclear facilities using low-yield nuclear weapons, the first such use since Hiroshima and Nagasaki. Although contamination could be limited, it would still mean the release of considerable radioactivity. Since the "children of the ashes" incident that resulted from the dropping of atomic bombs over Japan, several notable accidents have occurred-Chelyabinsk, Three Mile Island, and Chernobyl - that continue to demonstrate the terrible effects of such events. Fortunately, there have been no malicious attacks resulting in extensive destruction using radiological devices, but the threat of hazard remains. Consequently, the physical, financial, environmental, psychological, and political effects of a radiological terrorist attack should be estimated using informed opinions and evidence-based science. This is a test for international collaboration and between the Balkans and the European Union in the fields of human security and the control of terrorism, an area that all countries should focus on.

\section{Correspondence:}

Prof. Jeffrey Levett

E-maii: jlebet@nsph.gr
Author Affiliations

National Athens School of Public Health, Athens, Greece 